\title{
CSR Level Versus Employees' Attitudes towards the Environment
}

\author{
Magdalena Rojek-Nowosielska ${ }^{1, * \mathbb{D}}$ and Łukasz Kuźmiński ${ }^{2}$ \\ 1 Department of Strategic Management, Faculty of Management, Wroclaw University of Economics and \\ Business, Komandorska 118/120, 53-345 Wroclaw, Poland \\ 2 Department of Process Management, Faculty of Management, Wroclaw University of Economics and \\ Business, Komandorska 118/120, 53-345 Wroclaw, Poland; lukasz.kuzminski@ue.wroc.pl \\ * Correspondence: magdalena.rojek-nowosielska@ue.wroc.pl; Tel.: +48-71-3680-635
}

Citation: Rojek-Nowosielska, M.; Kuźmiński, Ł. CSR Level Versus Employees' Attitudes towards the Environment. Sustainability 2021, 13, 9346. https://doi.org/10.3390/ su13169346

Academic Editor: Andrea Pérez

Received: 15 July 2021

Accepted: 9 August 2021

Published: 20 August 2021

Publisher's Note: MDPI stays neutral with regard to jurisdictional claims in published maps and institutional affiliations.

Copyright: (c) 2021 by the authors. Licensee MDPI, Basel, Switzerland. This article is an open access article distributed under the terms and conditions of the Creative Commons Attribution (CC BY) license (https:// creativecommons.org/licenses/by/ $4.0 /)$.

\begin{abstract}
Are enterprises that achieve a higher level in the CSR continuum model more responsible towards the environment? This is the research problem of this paper. The purpose of the research was to identify whether (and if so, which of the independent variables $(X)$ indicate this) there is a relationship between a higher level of CSR and more responsibility towards the environment? The basis for determining the level of CSR is a proprietary CSR continuum model, built on the basis of the CMMI maturity model and the levels of moral development were according to Kohlberg. STATISTICA 12 was used for data analysis, using the chi-square test of independence and correspondence analysis. The results of the conducted research allow to notice that, in the research sample of 417 business entities, only in the case of two pairs of variables was a significant relationship between the studied variables noticeable. Thus, the obtained results allow for a positive answer to the question posed in the research problem, but only in the case of water management and waste disposal.
\end{abstract}

Keywords: environment; employees; water management; maturity; CSR; Kohlberg; CMM

\section{Introduction}

A significant numerical increase in the number of CSR publications can be observed, and a large variety of topics have been studied in the last dozen years. In addition, articles have been published that review current considerations related to CSR. For example, Low compiled key CSR definitions (from 1953 to 2009), as well as main topics related to this concept (among which human resources, shareholders, customers, suppliers, financial partners, public authorities, community and environment are listed) [1]. In turn, Lockett et al. analyzed research published in management literature in 1992-2002, and grouped topics related to CSR issues into four main threads: social responsibility, business ethics, environmental responsibility, and stakeholders' management [2].

Other authors, as a result of literature reviews of international journals on management, have identified such key areas under corporate responsibility as corporate social responsibility, ethics, environmental responsibility, and governance [3]. Dahlsrud [4] analyzed the content of existing CSR definitions. As a result of the research, he developed five dimensions of CSR (environmental, social, economic, stakeholder, voluntariness) and then, he determined the frequency at which these dimensions were invoked. An interesting list of key issues discussed in the literature in the field of CSR was made by Taneja, Taneja, and Gupta [5]. They grouped the most common issues into five key areas: (1) changing meaning, definitions, and models of CSR; (2) factors determining CSR initiatives; (3) measurement of corporate social performance; (4) impact of CSR on stakeholders and financial performance; (5) CSR in action. Each area was refined with other critical issues within the abovementioned framework. Thus, within area (1), CSR literature and developments in CSR were listed. In the second area, the authors pointed to factors contributing to the growth of CSR practices, the need for CSR in business, as well as the importance of CSR in 
business. The area related to the measurement of corporate social performance was further specified with issues such as considerations of CSR measuring, approaches to measuring corporate social performance, problems in measuring corporate social performance and approaches to assess CSR initiatives. Area (4) was refined with aspects such as the impact of CSR initiatives on corporate image, the impact of CSR initiatives on financial performance, and the impact of CSR initiatives on customers. Within the last area, the following key issues were identified: CSR practices across nations, CSR strategies, and problems in implementing CSR.

The issue of CSR maturity itself is rarely raised. There are examples of articles examining the correlation between company maturity and the degree of their involvement in social initiatives. For example, Withisuphakorn and Jiraporn [6] advanced a hypothesis that mature firms invest more in CSR than younger firms. In other words, they linked CSR to corporate lifecycles. They also noticed that as an enterprise's age increases, the scope of CSR involvement changes. Initially, enterprises become more responsible in matters concerning environmental awareness and diversity issues; however, as the years go by, enterprises become less engaged in terms of human rights and product safety. Other articles discuss issues such as the influence of maturity on CSR and sustainable innovation [7], sustainability and supply chain maturity models [8], maturity models concerning innovation [9], maturity models in the context of strategic management [10], and environmental management [11].

The subject literature also contains threads discussing CSR models and taking CSR levels into account. Usually, these are models that are constructed regarding the macro-scale and formulate general descriptions of CSR levels (not including references to the microand mesoscale). They usually discuss gradual levels that capture entities' involvement in pro-social initiatives, from "doing nothing" to "doing a great deal". In models where CSR is the main topic of consideration, there are stages mentioned, such as fight all the way, do only what is required, be progressive, and lead the industry [12]. Mirvis and Googins [13] defined the elementary, engaged, innovative, integrated, and transforming stages. According to Carlisle and Faulkner [14], we can enumerate developing awareness, promoting, initial implementation, and mainstreaming awareness. It is worth mentioning Visser's [15] very well-known stages: defensive, charitable, promotional, strategic and systemic. These models, as the main axis of considerations, can adopt corporate sustainability, which includes stages such as rejection, non-responsiveness, compliance, efficiency, strategic proactivity, sustaining organization [16] or pre-corporate sustainability, compliance- driven, profit-driven, caring, synergistic, and holistic [17]. Aggerholm and Trapp [18] indicated stages called first generation, second generation, and third generation. An interesting formulation of corporate sustainability levels comes from Dyllick and Muff's paper [19], where they described stages such as business-as-usual in the current economic paradigm, business sustainability 1.0—refined shareholder value management, business sustainability 2.0 - managing for the triple bottom line, and business sustainability 3.0- true sustainability.

Based on the considerations discussed above, a research gap can be seen in the form of a lack of discussion on the issue of the maturity of corporate social responsibility, as well as the methods of measuring the level of CSR maturity, and, as a result, empirical experience enabling determination of the current level of maturity of corporate social responsibility. Taking into account the current concern for the environment of all entities (both private and public) [20-26], as well as society as a whole [27-29], the research problem to be addressed in this article is presented in the form of a question: Are the enterprises achieving a higher level in the CSR continuum model more responsible towards the environment? Therefore, the purpose of the article is to present the empirical verification of the relationship between the CSR level and the company's attitude towards the environment.

By purchasing the database of companies, we obtained access to 38,390 entities and invited them to participate in the research. The selection criterion was active operation of the business at the time of the survey. In addition, we obtained knowledge, i.a., regarding 
the company size (measured by the number of employees), origin of capital, and the year of foundation, but this paper does not discuss these details. The research tool was completed by a person knowledgeable in CSR activities performed by the researched entities.

Out of the five independent variables $\left(X_{1}\right.$-the analysis and assessment of the company's impact on the environment, $X_{2}$-conscious shaping of the rational management of electricity, $X_{3}$-conscious shaping of the rational management of water, $X_{4}-$ conscious shaping of the rational management of office materials, and $X_{5}$-conscious shaping of the rational management of the company guidelines in meeting its waste disposal obligation), only two were covered by further analysis. In the area of water management $\left(X_{3}\right)$ and waste management $\left(X_{5}\right)$, along with enterprises achieving a higher level in the CSR continuum model, the examined entities were more responsible for the environment.

In order to achieve the above-mentioned goal, the first part of the article presents the theoretical background showing the CSR continuum model (developed by Magdalena Rojek-Nowosielska), the Kohlberg's model, and the capability maturity model providing a basis for empirical research. The next part discusses the research methodology used in the empirical verification of the research problem, which is followed by the research findings, discussion, and conclusions.

\section{Theoretical Background}

The concept of human moral development proposed by Kohlberg constituted a pillar for developing the theoretical framework of the levels in the authors' model of the CSR continuum. It should be emphasized that this concept brought about a heated scientific debate in the source literature [29-38]; e.g., the legitimacy of placing human principles above law and society was put into question. In addition, a strong influence of cultural determinants on the achievement of certain moral development levels, especially evident in Eastern cultures, was highlighted. Therefore, separate levels of moral development should not apply to other types of cultures without previously made assumptions and descriptions of potential cultural differences [39] (pp. 118-136).

Kohlberg, in his concept of the moral development of man, proposed six stages of man's development, which are grouped into three main levels consisting of a further two sub-levels each (based on [40] (pp. 630-646)). The first level—preconventional—consists of two sub-levels: obedience and punishment and also individualism and exchange. Both sub-levels refer to the situation in which the moral sources of human behavior are sought in the desire to avoid punishment or to receive a reward (obedience and punishment) or in the pursuit of maximum benefits (individualism and exchange). As a result of such an approach, a person making a specific decision is not especially guided by loyalty, respect, or internal conviction about the need for a given behavior (which is anchored in the existing social norms and values), but rather by the individual benefits or fear of possible punishment.

The second level—conventional—describes people who are no longer guided by fear and the desire to avoid punishment in their decisions, but rather the social expectations towards them and the decisions they make. Social judgments are associated with the decisions made, which, in consequence, classify a given person as "good" or "bad" in light of social expectations. The conventional level is divided into two sub-levels: a sub-level of good interpersonal relationships and a sub-level of maintaining social order. The first sub-level (of good interpersonal relations) is sometimes also referred to as the interpersonal one due to the subordination of one's decisions to the image of appropriate behavior accepted by the society. People from the second sub-level (maintaining social order) have other motives. For them, it is important to obey legal regulations and to respect the authorities and social rules that guarantee (in accordance with their beliefs) the maintenance of social order.

The third level—postconventional—refers to people whose behaviors result from the internal belief that their decisions are right. It is the level of moral principles voluntarily accepted by people, not because society determines their rightness or there is a fear of 
receiving punishment, but because they know what moral righteousness means, what it results from and how it should be respected. This level consists of the sub-level of the social contract and individual rights and the sub-level of universal principles. The first of the distinguished sub-levels includes people who are aware of the existence of different individuals in society, having different expectations and moral values, but who assume that they are rational individuals and, on this basis, postulate the existence of two basic reasons:

1. Firstly, all participants of social life expect the respect of fundamental rights, i.e.: freedom and protection of life;

2. Secondly, all participants of social life expect democratic procedures when changing unfair rules and attempting to improve social life.

On the sub-level of universal principles, moral decisions result from the principles voluntarily chosen by people, as an independent choice of each individual. In his later works, Kohlberg refrained from isolating this sub-level, calling it "theoretical" and finding it very difficult to implement in reality. Therefore, the stage of the social contract and individual rights is a reflection of this sub-level [41] (p. 28).

The CMM concept is another point of reference for the CSR continuum model. Originally, the capability maturity model was developed for software organizations to provide them with guidance on how to gain control over their processes for development and how to arrive at excellent results. CMM was designed to guide software organizations in selecting process improvement strategies by determining the existing process maturity and identifying the issues most critical to software quality and process improvement. By focusing on a limited set of activities and working aggressively to achieve them, an organization can steadily improve its organization-wide software development process to enable continuous and lasting benefits in terms of software process capability [42] (p. 5).

Within the scope of the model, the following five main process maturity levels were identified-initial, managed, defined, quantitatively managed, and optimizing.

At the lowest level-initial-the processes and their key elements are described in a chaotic manner and are devoid of any formal procedures. When the processes are implemented without the previously specified guidelines, tasks may change, causing uncertainty in their final results. Schedules, budgets, or product quality are, in most cases, unpredictable. The success in project realization depends on individual efforts undertaken by project managers and project team members. When these capable and skilled managers leave a project, their stabilizing influence vanishes with them. It is at this stage, therefore, that success is fully dependent on the capabilities of individuals, their skills, knowledge, and level of motivation. At the maturity level 2-managedselected processes are institutionalized and managed in an organization, which allows an organization to become more effective. The strategy and work plans are defined and the work is monitored and controlled to ensure that the service (or the product) is delivered as planned. The process discipline reflected in the managed maturity level helps to ensure that the existing practices are retained during times of stress. At maturity level 3-defined - the processes for managing work are defined. The processes are well characterized, understood, and described in standards, procedures, tools, and methods. The scope of standards, process descriptions, and procedures is an important distinction between maturity levels 2 and 3. Another critical distinction between the discussed levels is a more rigorous description of the processes at the defined level in comparison to the managed level. A defined process should include the purpose, inputs, entry criteria, activities, roles, measures, verification steps, outputs, and exit criteria. At maturity-the quantitatively managed level—quantitative objectives for quality and process performance are established and used as crucial criteria in process managing. For the last leveloptimizing - an organization should continue improving its achievements in realizing tasks and processes. The previously established quantitative criteria and their ongoing confrontation with existing market requirements should act as an incentive for future changes and a trigger the setting of new goals [43] (pp. 27-29), [44] (p. 3), [45] (p. 3) (the paragraph about the CMM maturity model description was originally printed in [46]). 
The CSR continuum model developed by Rojek-Nowosielska, organizes CSR levels in theoretical terms (Figure 1). The perspective of this model focuses on a specific enterprise (examining its level of social responsibility), not on a comprehensive (macro) approach, which usually allows assigning some enterprises to a specific model. The theoretical approach was developed in reference to the level of Kohlberg's moral development and the CMM maturity model [46]. The levels of enterprise development that are in line with the CSR concepts can be referred to as the three main levels, which have been conventionally marked with the following symbols: $\mathrm{C}$-common, $\mathrm{S}$-superior, $\mathrm{R}$-remarkable.

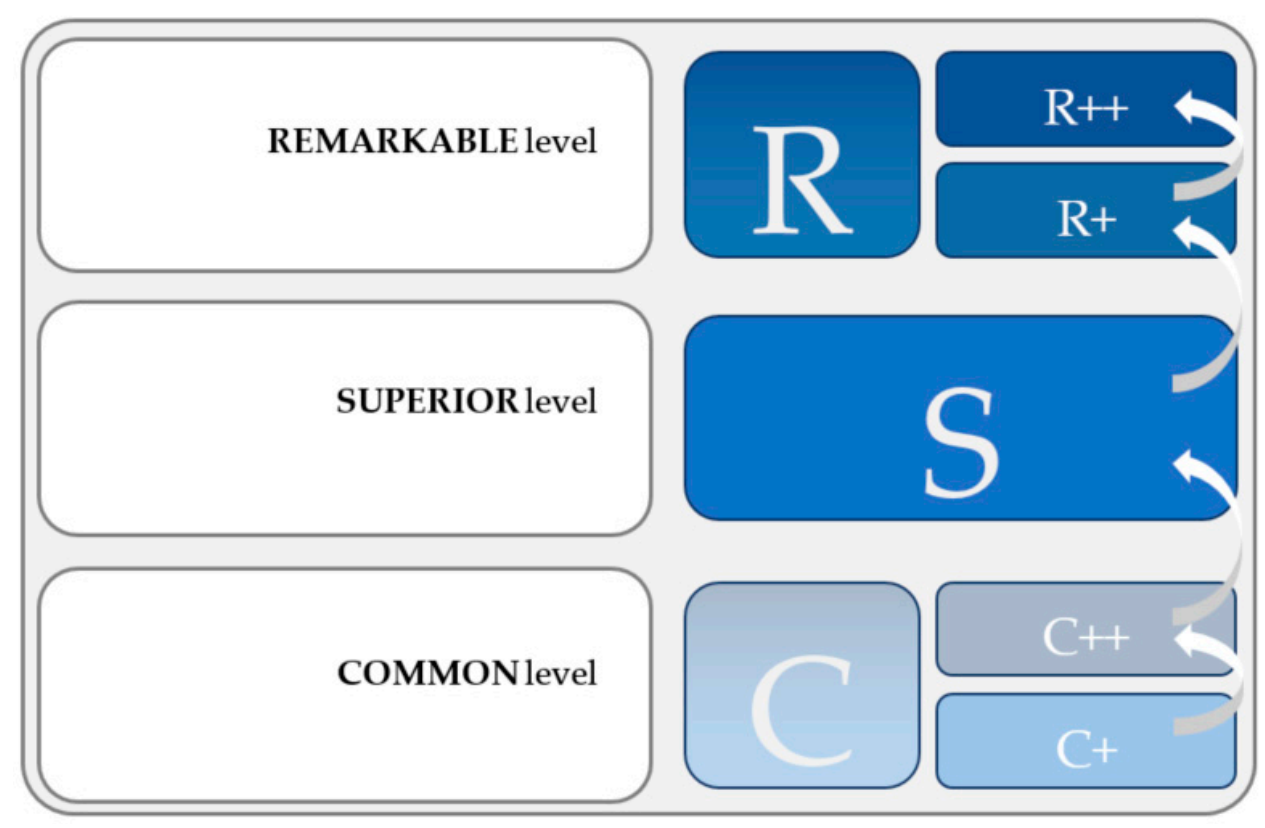

Figure 1. Levels of CSR continuum model. Source: [46], (p. 38).

The first level $-\mathrm{C}$ (partial—common) indicates that the basic assumptions of the model were achieved owing to more thoughtful, planned activities, and, as a result the planned activities, may show features of repeatability; managers may base their decisions on the acquired experience. This level, due to its complexity, has been divided into two sub-levels called $\mathrm{C}+$ and $\mathrm{C}++($ Table 1$)$. This specification enables a more precise definition of the degree of involvement of a given entity in the implementation of CSR assumptions. The main determinant at this stage is the lack of formalization and acting spontaneously. The $\mathrm{C}+$ level includes these entities, which do not use experience while implementing the CSR concept and perform activities guided by temporary inspiration. The $\mathrm{C}++$ level, in turn, is characterized by entities which, despite a lack of formal records or ordering documents, use the experience gained, thus resulting in a faster implementation time, greater effectiveness, and efficiency of operations that can be observed. Therefore, an attempt can be made to state that there has been a transition from chaotic activities to more thoughtful ones, due to which the activities performed may show features of repeatability and managers may base their decisions on the experience gained when making decisions.

The second level-S (standard-superior) is the level at which the most important activities identified in the previous stages are, not only repeatable, but above all, are included in the relevant documents and procedures. The resulting documents (if, of course, they are not just a series of unread reports) prove to be careful considerations of the described problems and the selection of such solutions that, taking into account the current conditions, constitute optimal solutions. One of the most interesting aspects of running a business is the constant fluctuation of factors affecting an organization, which leaves little room for routine activities. However, the same factors that may constitute the merits of a given phenomenon, from a different perspective, may speak against it. This is the case with the business environment. That is why, documents prepared at the standard level, 
due to changing conditions in which a company operates, should be systematically verified and updated.

Table 1. Description of the model levels.

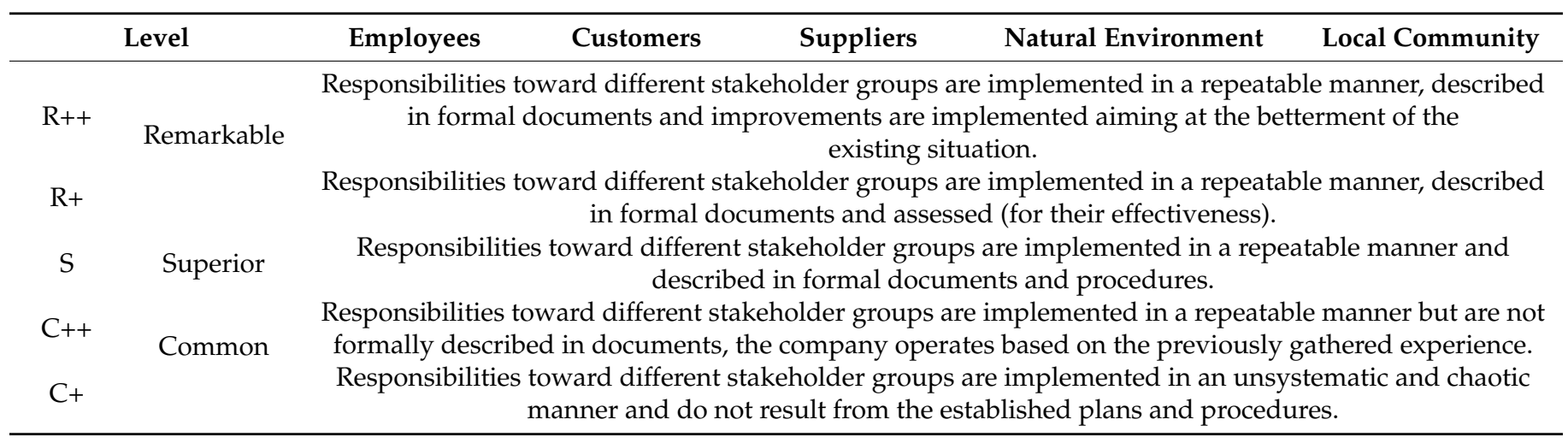

The last level- $\mathrm{R}$ (extended—remarkable) was developed in line with these assumptions. In order to accurately indicate the changes taking place in a given enterprise, the model approach to an organization qualified at the highest level includes this stage and has two sub-levels: $\mathrm{R}+$ and $\mathrm{R}++$. An entity at the $\mathrm{R}+$ level is characterized by the repetition of tasks included in relevant documents organizing and improving every-day functions. In addition, continuous observation and analysis of ongoing activities are carried out in order to adequately modify, improve, and update existing solutions at the $\mathrm{R}++$ level relative to the changes taking place in the market and the expectations of stakeholders.

Apart from the detailed description of the model, it should be added that the lowest level of the model is characterized by chaotic, unthoughtful actions, and the highest by planned and often improved actions. In other words, at the C+ level, the company does not know why it makes mistakes, while when reaching the level of $\mathrm{R}++$, the company knows why it does not commit them.

The continuum model has additionally separated areas (employees, customers, suppliers, natural environment, local community), within which a more detailed study can be conducted. This issue is discussed in more detail in the article by Rojek-Nowosielska [47] (pp. 123-133). Due to the scope of the article and the implementation of the research problem addressed in this article, the research tool is not discussed in detail.

\section{Materials and Methods}

\subsection{Sample}

Prior to the main research, a pilot study was conducted, which allowed eliminating some mistakes (the content of the questions was improved, the definitions of stakeholders, voluntary initiatives, social initiatives/projects were explained at the initial part of the tool).

In order to answer our question (are the enterprises achieving a higher level of CSR more responsible towards the environment?), 417 entities were surveyed (enterprises operating in Poland) over the years 2014-2017. To conduct the cross-sectional study, a database of companies was purchased, which had 38,390 records, and an invitation to participate in a survey was sent to them. The selection criterion was operating a business at the time of the survey. The invitation included a link to an electronic version of the tool (the study was conducted applying the method of a diagnostic survey with a questionnaire as a research tool). Due to the fact that access to the tool was open (through information on the website), the entities willing to participate in the study could fill in the questionnaire form on an ongoing basis and answer the questions asked. The research tool was completed by a person knowledgeable in the CSR activities performed by the researched entity. 


\subsection{Dependent Variable}

Our study, using the questions included in the questionnaire, checked how the level of CSR (variable $Y$ ) changes, depending on the implementation of tasks related to environmental care by a given company.

\subsection{Independent Variable}

In order to answer the question included in the research problem (are the enterprises achieving a higher level in the CSR continuum model more responsible towards the environment?), the questions allowed possible variants of answers related to the level scale in Kohlberg's model. The measuring of responsibility towards the environment was possible by examining five independent variables $(X)$. The list of dependent and independent variables is presented in Table 2.

Table 2. Qualitative variables used in the study.

\begin{tabular}{cc}
\hline Designation & Detailed Specification of the Variable \\
\hline$Y$ & CSR level \\
$X_{1}$ & Does your company analyze and assess the company's environmental impact? \\
$X_{2}$ & Does your company consciously shape the rational management of electricity? \\
$X_{3}$ & Does your company consciously shape the rational management of water? \\
$X_{4}$ & Does your company consciously shape the rational management of office supplies? \\
$X_{5}$ & Please indicate the reasons guiding the company when implementing the obligation to utilize waste \\
\hline
\end{tabular}

Among the variables included in the study, in the case of variable $(Y)$, the examined enterprises were classified using ordinal measurement, and in the case of other variables, the nominal measurement was used for classification. The analysis of the obtained data was carried out with the use of STATISTICA 12 software.

\subsection{Data Analysis Stages}

Data analysis was carried out in two stages. In the first stage, the relationship between five pairs of variables was checked. Each pair consists of the variable $Y$ and one of the variables $X_{1}, \ldots, X_{5}$. The existence of dependencies between the variables is checked using a commonly applied statistical tool in the form of the chi square test of independence. Using this test, five hypotheses about the lack of dependence between the studied variables are verified: $H_{0}$ : the variables $Y$ and $X_{i}$ are independent, $i=1, \ldots, 5$, against alternative hypotheses in which the correlation between the variables is found: $\mathrm{H}_{1}$ : the variables $Y$ and $X_{i}$ are dependent, $i=1, \ldots, 5$. The chi-square test of independence will be carried out in two versions: chi-Pearson square and chi-maximum likelihood square. The latter test is performed in the case when for any of the pairs of analyzed variables in the multi-way table there is an expected count less than or equal to 5 [48].

In the second stage of the study, pairs of variables for which a significant relationship resulting from the first stage of the study is confirmed, will be subject to correspondence analysis. The chi-square tests of independence, which are carried out as part of the first research stage, are intended to demonstrate the possible relationship between the pairs of the examined qualitative variables, but they do not describe the nature of the relationships between the categories of individual variables. The identification of the nature of these connections is necessary to solve the research problem defined in the study. In order to identify the relationships between the categories of analyzed pairs of qualitative variables in detail, a descriptive - exploratory correspondence analysis technique is performed. The analysis in question enables a simple and intuitive inference about the existing relationships between the categories of individual variables under study. Considering the above statement in the language of statistical engineering, it can be said that the correspondence analysis gives the possibility of inferring about the relationship between the columns and rows of the two-way table. An important advantage of this method is that it graphically shows the relationships between rows and columns of the multi-way tables of different 
sizes as points in a 2- or 3-dimensional space. Additionally, it can be used for both quantitative and qualitative data. As one of the few methods belonging to the group of multivariate data analysis, it does not impose clear data requirements, such as the minimum sample sizes for individual variables and their profiles. Its disadvantage is the inability to verify the significance of the relationship between the studied variables. For that reason, as a supplement to the conducted study, the chi-square test of independence was additionally used to verify the significance of the relationship between the variables. In addition, to assess the strength of the verified dependence, a measure in the form of the $C$ contingency coefficient was used. It is one of several measures of the relationship between variables that can be used for contingency tables greater than $2 \times 2$. Details on the theoretical basis of correspondence analysis can be found in [49].

\section{Results}

The results of Pearson's $\chi^{2}$ independence tests and the maximum likelihood $\chi^{2}$ test of independence in the form of $p$-value together with the contingency coefficient $C$ illustrating the strength of the relationship between the analyzed variables are presented in Table 3 .

Table 3. The results of the $\chi^{2}$-Pearson's independence tests and the maximum likelihood in the form of $p$-value and the values of the $C$ contingency coefficient for the studied variables.

\begin{tabular}{cccc}
\hline Variable Pairs & $\chi^{2}$-Pearson & $\chi^{2}$-NW & C \\
\hline$Y-X_{1}$ & 0.498 & 0473 & 0.113 \\
$Y-X_{2}$ & 0.319 & 0.295 & 0.129 \\
$Y-X_{3}$ & $0.00001^{* *}$ & $0.00001^{* *}$ & 0.273 \\
$Y-X_{4}$ & 0.901 & 0.873 & 0.072 \\
$Y-X_{5}$ & $0.0026^{* *}$ & $0.0007^{* *}$ & 0.215 \\
\hline
\end{tabular}

If the value of $p$-value is ${ }^{* *}$, it means that the relationship between the analyzed pair of variables is at the significance level $\alpha=0.01$.

The results of the chi-square tests of independence presented in Table 3 confirmed the relationship between the two pairs of analyzed variables and at the same time confirmed the absence of correlation between the other three pairs of variables involved in the study. The pairs of variables showing a relationship include $\left(Y, X_{3}\right)$ and $\left(Y, X_{5}\right)$, while the pairs with no relationship are $\left(Y, X_{1}\right),\left(Y, X_{2}\right)$ and $\left(Y, X_{4}\right)$.

Comparing the obtained results from the first stage of the study to the detailed definitions of the variables used in the study (Table 2), it can be concluded that the answers to the question regarding the awareness of rational water management in the enterprise and the question about the motives behind the implementation of the waste disposal obligation depend on the achieved level of CSR at which the companies under study are located. At the same time, the results obtained in the first stage of the study allow concluding that the answers to the remaining three questions are independent of the achieved CSR level.

Due to the results obtained in the first stage of the study, only these pairs of variables that showed significant interdependence were qualified for the second stage, i.e., correspondence analysis. Correspondence analysis will cover pairs $\left(Y, X_{3}\right)$ and $\left(Y, X_{5}\right)$. Correspondence analysis takes place in seven main steps. Due to the fact that nowadays computer packages are used for statistical research, there is no need to describe each of them in turn, because some steps are performed simultaneously by a computer program.

First, the analysis of correspondence covered the pair of variables $\left(Y, X_{3}\right)$, i.e., the level of CSR in the surveyed companies, and answers to the question about the awareness of rational water management.

\subsection{Analysis of the Relationship between the CSR Level and the Awareness of Rational Water Management}

The first step to be taken in the correspondence analysis, despite the use of computer packages for calculations, is to determine the dimension of space that will best reflect the 
actual relationships between the different categories of the pair of qualitative variables included in the study. There is no single criterion for selecting the number of space dimensions, it is an individual matter. There are many criteria in the literature, of which three are the most popular: scree, interpretability, and similarity. In the conducted research, the dimension of space will be determined on the basis of the scree criterion. For the purposes of deciding on the size of space, a chart of the scree was made (Figure 2) and the generalized singular values and eigenvalues presented in Table 4 were calculated.

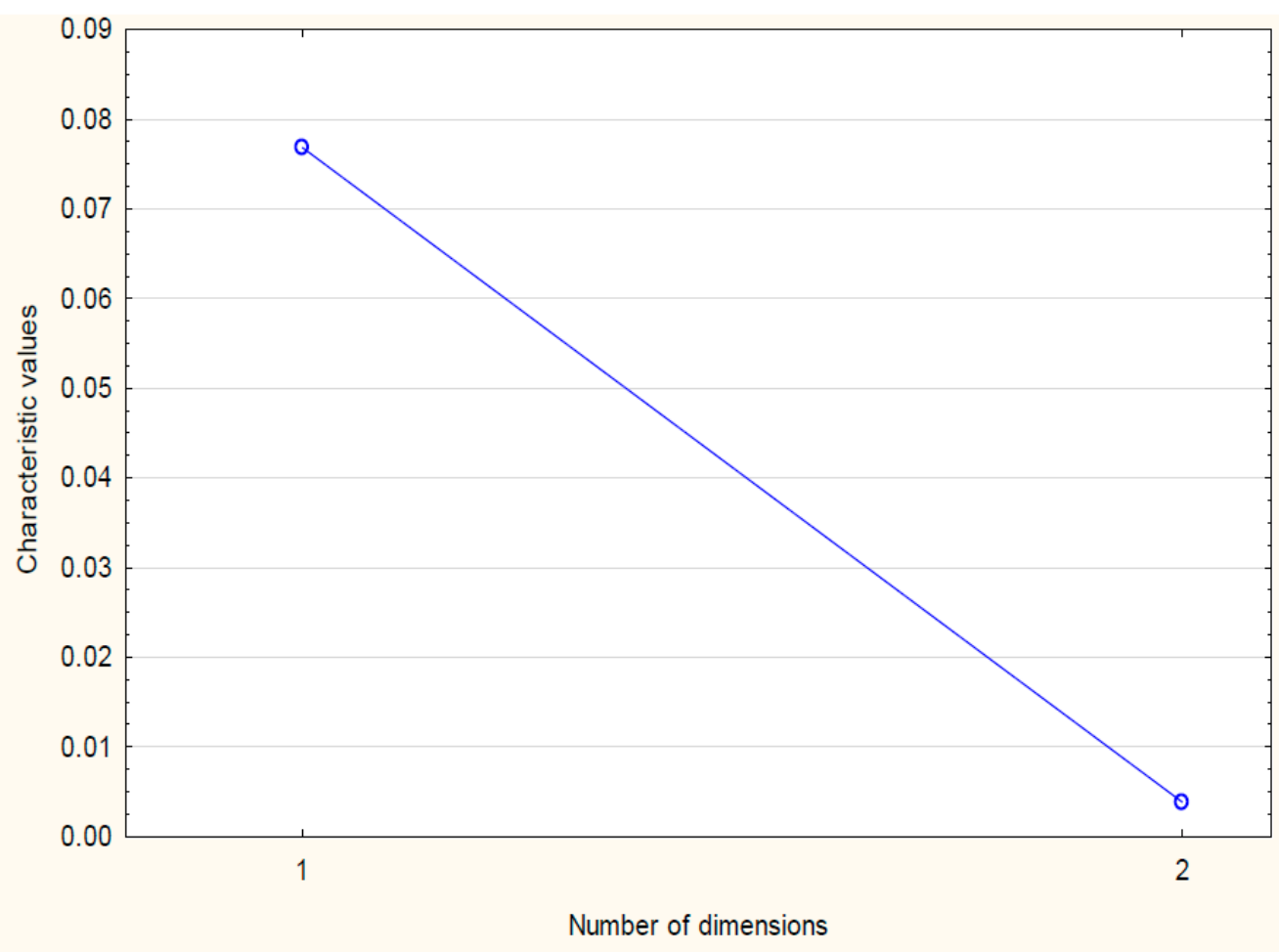

Figure 2. Characteristic values for a pair of variables $Y$ and $X_{3}$.

Table 4. Eigenvalues, total inertia, and generalized singular values for a pair of variables $Y$ and $X_{3}$.

\begin{tabular}{|c|c|c|c|c|c|}
\hline \multirow[t]{2}{*}{$\begin{array}{l}\text { Number of } \\
\text { Dimension }\end{array}$} & \multicolumn{5}{|c|}{$\begin{array}{c}\text { Total Inertia: } 0.08070 \\
\text { Chi-Square: } 33,653 \\
d f: 6 \\
p \text {-Value: } 0.00001\end{array}$} \\
\hline & Singular Values & $\begin{array}{c}\text { Characteristic } \\
\text { Values }\end{array}$ & $\begin{array}{l}\text { Percentage of } \\
\text { Inertia }\end{array}$ & $\begin{array}{l}\text { Cumulative } \\
\text { Percentage }\end{array}$ & Chi Square \\
\hline 1 & 0.2772 & 0.0768 & 95.2425 & 95.2425 & 32.05175 \\
\hline 2 & 0.0619 & 0.0038 & 4.7574 & 100 & 1.6010 \\
\hline
\end{tabular}

To determine the dimension, using the scree eigenvalues chart, one should look for a point where the eigenvalue decline changes its slope from steep to very close to horizontal. In the analyzed case, there is no such change in the graph, because there are only two eigenvalues, therefore it is assumed that the two-dimensional space will be optimal.

The results in Table 4 also confirm that the second dimension was the right choice. Looking at the values showing the percentage of inertia, it can be seen that the first dimension allows for the reconstruction of $95.24 \%$ of the total inertia. After taking into account the second dimension, the percentage of explained inertia increases to $100 \%$. This means that $100 \%$ of the original information was reconstructed in the reduced space. Ultimately, the two-dimensional space is accepted in the study. 
For the $X_{3}$ variable, four variants of answers were possible: (1) no activity is undertaken; (2) it is undertaken due to economic issues (e.g., savings); (3) it is undertaken due to the image-related issues, and (4) it is undertaken for the sake of the environment. Having adopted the above-mentioned four possible answers for the below data analysis, for the summary purposes they were named accordingly: not, economics, image, environment.

The coordinates of rows and columns for each variable category of the multi-way table were calculated in the next stage of correspondence analysis. The results of these calculations are presented in Table 5 for rows (CSR levels) and in Table 6 for columns (attributes of independent variables). Additionally, Tables 5 and 6 contain other statistics facilitating the interpretation of the obtained results and allowing the quality evaluation of the obtained solution.

Table 5. Row coordinates and contribution to inertia.

\begin{tabular}{cccccccccc}
\hline $\mathbf{1}$ & $\mathbf{2}$ & $\mathbf{3}$ & $\mathbf{4}$ & $\mathbf{5}$ & $\mathbf{6}$ & $\mathbf{7}$ & $\mathbf{8}$ & $\mathbf{9}$ & $\mathbf{1 0}$ \\
\hline & Coefficient 1 & Coefficient 2 & Weight & Quality & Resp. Abs. & Abs. Resp. & Cos $^{2}$ & Abs. Resp. & Cos $^{2}$ \\
& & & & & 1 & 1 & 2 \\
2 & 0.049 & 0.646 & 0.538 & 0.354 \\
$\mathrm{C}$ & -0.095 & 0.07 & 0.412 & 1.00 & 0.072 & 0.049 & 0.461 & 0.274 \\
$\mathrm{~S}$ & -0.099 & -0.06 & 0.477 & 1.00 & 0.08 & 0.061 & 0.726 & 0.00004 & 0.001 \\
$\mathrm{R}$ & 0.787 & -0.001 & 0.11 & 1.00 & 0.847 & 0.889 & 0.999 & 0.004 \\
\hline
\end{tabular}

Table 6. Column coordinates and contribution to inertia.

\begin{tabular}{|c|c|c|c|c|c|c|c|c|c|}
\hline 1 & 2 & 3 & 4 & 5 & 6 & 7 & 8 & 9 & 10 \\
\hline & $\begin{array}{c}\text { Coefficient } \\
1\end{array}$ & $\begin{array}{c}\text { Coefficient } \\
2\end{array}$ & Weight & Quality & Resp. abs. & $\begin{array}{c}\text { Abs. Resp. } \\
1\end{array}$ & $\begin{array}{c}\operatorname{Cos}^{2} \\
1\end{array}$ & $\begin{array}{l}\text { Abs. Resp. } \\
2\end{array}$ & $\begin{array}{c}\operatorname{Cos}^{2} \\
2\end{array}$ \\
\hline not & 0.058 & 0.051 & 0.503 & 1.00 & 0.038 & 0.023 & 0.562 & 0.352 & 0.438 \\
\hline economics & -0.066 & -0.015 & 0.294 & 1.00 & 0.017 & 0.017 & 0.948 & 0.018 & 0.052 \\
\hline environment & -0.352 & -0.094 & 0.160 & 1.00 & 0.265 & 0,26 & 0.932 & 0.376 & 0.068 \\
\hline image & 1.149 & -0.154 & 0.040 & 1.00 & 0.678 & 0.7 & 0.982 & 0.251 & 0.018 \\
\hline
\end{tabular}

First, the results for the rows and columns presented in Tables 5 and 6 will be analyzed. The values in the fourth column of both tables show the quality of the individual row and column profiles. In other words, this measure informs about the importance of particular categories of the researched variables placed in rows and columns. Thus, the $S$ level is the most important for row profiles, and the not level for column profiles. The values placed in the next, i.e., fifth columns, of both tables above show the representation quality of individual rows and columns in the selected space with a smaller, i.e., second, dimension. The values of this measure for all rows and columns in the conducted study reach the value of 1 , which proves them being very well mapped in the selected two-dimensional space. The sixth columns of both analyzed tables contain measures of relative inertia for all row and column categories. These measures show, separately for the columns of rows, the share of individual row and column categories in the overall inertia. These measures for columns and rows separately can be treated as percentages since the values of these measures in both columns sum up to 1 . For rows, the R category has the largest share in the total inertia and for the columns it is the image. In the seventh and ninth columns of Tables 5 and 6, there are measures showing the share of individual points in the overall inertia of a given dimension ( 1 or 2 ), while the eighth and tenth columns contain measures showing the share of a given dimension in the individual inertia of points in rows and columns.

In the last part of the second stage of the study, the analysis of the two-dimensional graph showing the coordinates of the row and column profiles (Figure 3) is presented. Such a chart is called a symmetric map. This chart shows two axes corresponding to the two dimensions adopted in the correspondence analysis. When analyzing the chart showing the coordinates of row and column profiles, it should be remembered that the distance between points showing profiles of different types cannot be compared, i.e., the distance 
between a point showing one of the row profiles and the point showing a specific column profile cannot be juxtaposed. However, it is permissible to interpret the position of a point representing one type of profile with respect to all profile points of the other.

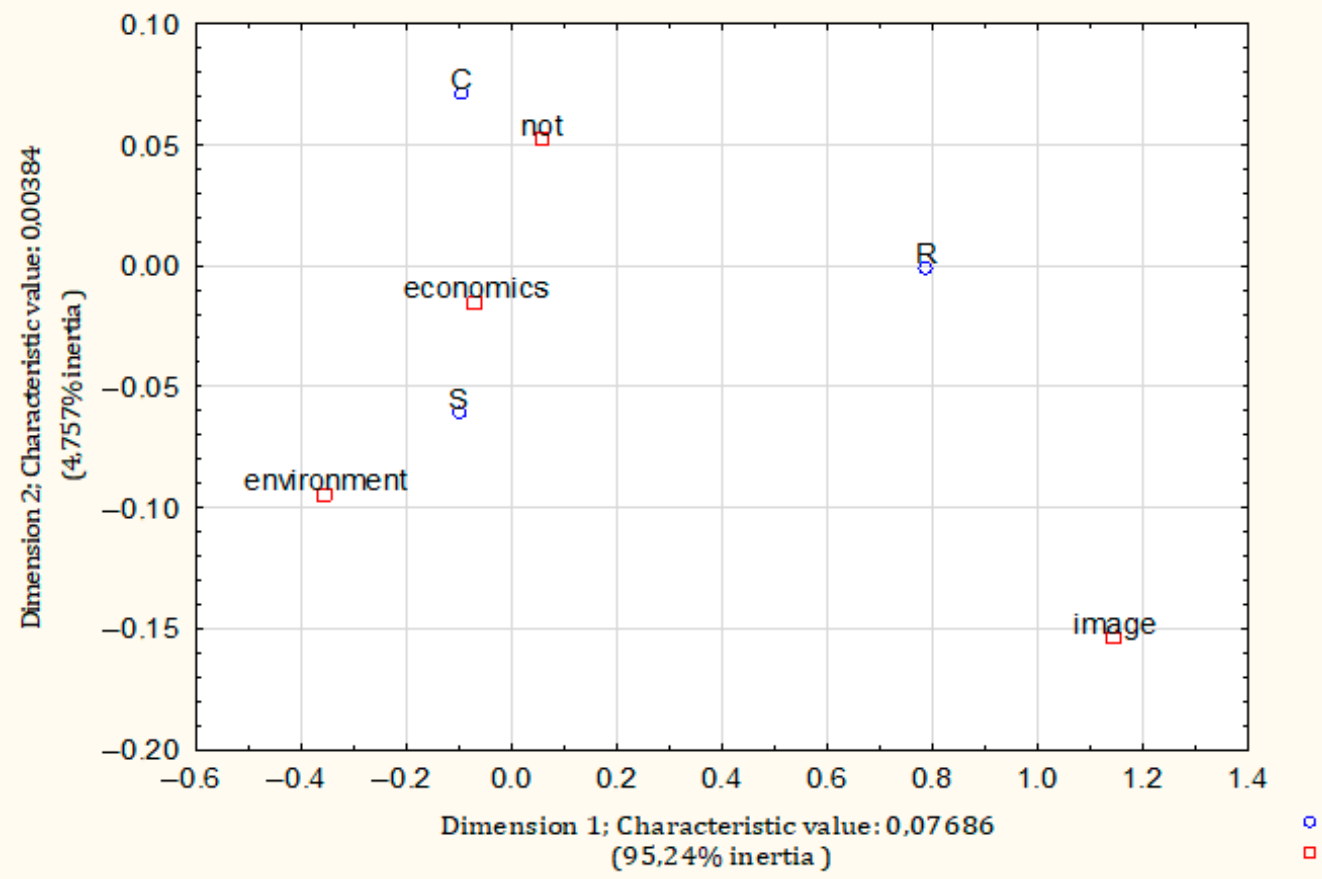

Figure 3. Two-dimensional chart of row and column coordinates for $Y$ and $X_{3}$.

Moving on to the interpretation of individual dimensions, we will start with the first dimension represented by the horizontal axis in Figure 3 as it has the largest share (95.24\%) in the total inertia (variance) (see Table 4). In the chart, the horizontal axis that represents the first dimension distinguishes two groups among the row profiles. To the right of its center, there are enterprises where the CSR criterion reaches the R level. The second group includes enterprises that achieve the $\mathrm{C}$ or $\mathrm{S}$ level in the continuum model. These points are additionally located close to the center of the axis, which means that both $C$ and $S$ profiles are close to the average profile. The second vertical axis is not considered in this detailed analysis because there is too little variation it explains compared to the first axis.

Among the column profiles, the axis representing the first dimension in the chart identifies two groups of companies. On the right-hand side of the center, there are companies that do not carry out conscious activities related to rational water management and the companies which carry out these activities for the purpose of obtaining or maintaining a good corporate image alone. The first group is definitely more numerous and the location of the point showing the profile of these enterprises indicates that this profile is close to the average profile. The location of the point illustrating the profile of enterprises conducting activities only for the purposes of good image, far to the right of the center of the axis, also proves a very small number of such enterprises in relation to the studied sample. Then, on the left, there are companies that carry out conscious activities related to rational water management, motivating it with the need to show concern for the environment and with economic factors.

4.2. Analysis of the Dependence of the Level of CSR and the Motives for the Implementation of the Need for Waste Disposal

In the next part of the second stage of the research, the analysis of the correspondence between the variable showing the level of CSR in the companies that participated in the survey $(Y)$ and the variable reflecting the responses of individual companies regarding the motive behind the implementation of the waste disposal obligation $\left(X_{5}\right)$ was carried out. 
The results of the correspondence analysis for the pair of variables $\left(Y, X_{5}\right)$ will be presented in the same way as for the previous pair of variables, however, in a reduced volume due to the limited scope of the article (Figure 4).

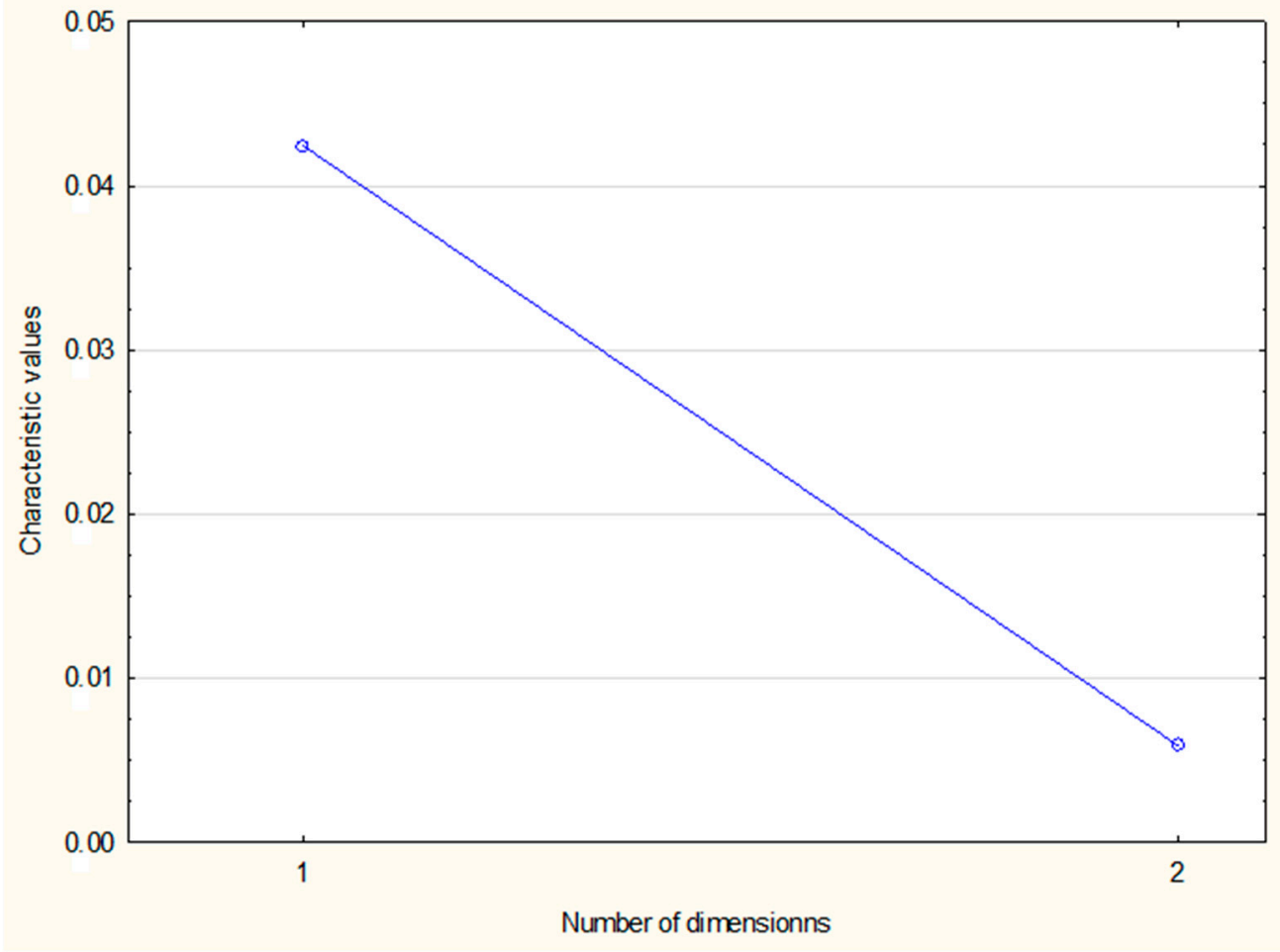

Figure 4. Characteristic values for a pair of variables $Y$ and $X_{5}$.

Based on the scree chart for a pair of variables $\left(Y, X_{5}\right)$ (Figure 4$)$, as well as the generalized singular values and eigenvalues presented in Table 7 , a decision was made to choose the two-dimensional space as the optimal one for further analysis of this pair of variables.

Table 7. Eigenvalues, total inertia, and generalized singular values for a pair of variables $Y$ and $X_{5}$.

\begin{tabular}{|c|c|c|c|c|c|}
\hline \multirow[t]{2}{*}{$\begin{array}{l}\text { Number of } \\
\text { Dimension }\end{array}$} & \multicolumn{5}{|c|}{$\begin{array}{c}\text { Total Inertia: } 0.04837 \\
\text { Chi-Square: } 20.172 \\
d f: 6 \\
p \text {-Value: } 0.00259\end{array}$} \\
\hline & Singular Values & Characteristic Values & $\begin{array}{l}\text { Percentage of } \\
\text { Inertia }\end{array}$ & $\begin{array}{l}\text { Cumulative } \\
\text { Percentage }\end{array}$ & Chi Square \\
\hline 1 & 0.2060 & 0.0424 & 87.76 & 87.76 & 17.703 \\
\hline 2 & 0.0769 & 0.0059 & 12.23 & 100 & 2.468 \\
\hline
\end{tabular}

For the $X_{5}$ variable, possible variants of the respondents' answers are as follows: (1) no activity is undertaken; (2) it is undertaken due to legal requirements; (3) it is undertaken due to image-related issues, and (4) it is undertaken due to the need of being honest. Having adopted the four possible answers for the data analysis below, they were summarized as: not, law, image, and fair.

Tables 8 and 9 contain the coordinate values for the rows-Table 8 and columnsTable 9, respectively. Analyzing the results collected in the fourth columns of both tables, it can be seen that the law profile has the highest quality for the column profiles. This means that from among the categories of the $X_{5}$ variable, the $X_{5}$ law category is of the highest 
importance. The results obtained for the row profiles are the same as for the analysis of the pair of variables $\left(Y, X_{3}\right)$.

Table 8. Row coordinates and contribution to inertia.

\begin{tabular}{cccccccccc}
\hline $\mathbf{1}$ & $\mathbf{2}$ & $\mathbf{3}$ & $\mathbf{4}$ & $\mathbf{5}$ & $\mathbf{6}$ & $\mathbf{7}$ & $\mathbf{8}$ & $\mathbf{9}$ & $\mathbf{1 0}$ \\
\hline & Coefficient 1 & Coefficient 2 & Weight & Quality & Resp. Abs. & Abs. Resp. 1 & Cos $^{2}$ & \multicolumn{2}{c}{ Abs. Resp. $_{\text {Cos }}^{2}$} \\
& & & & & & 1 & 2 \\
$\mathrm{C}$ & -0.245 & 0.005 & 0.412 & 1.00 & 0.514 & 0.585 & 0.999 & 0.002 & 0.0004 \\
$\mathrm{~S}$ & 0.165 & -0.051 & 0.477 & 1.00 & 0.295 & 0.306 & 0.910 & 0.216 & 0.09 \\
$\mathrm{R}$ & 0.204 & 0.204 & 0.110 & 1.00 & 0.190 & 0.108 & 0.498 & 0.782 & 0.502 \\
\hline
\end{tabular}

Table 9. Column coordinates and contribution to inertia.

\begin{tabular}{lccccccccc}
\hline $\mathbf{1}$ & $\mathbf{2}$ & $\mathbf{3}$ & $\mathbf{4}$ & $\mathbf{5}$ & $\mathbf{6}$ & $\mathbf{7}$ & $\mathbf{8}$ & $\mathbf{9}$ & $\mathbf{1 0}$ \\
\hline & Coefficient 1 & Coefficient 2 & Weight & Quality & Resp. abs. & Abs. Resp. 1 & Cos $^{2}$ & \multicolumn{1}{c}{ Abs. Resp. } & Cos $^{2}$ \\
& & & & & & 1 & 2 \\
not & -0.153 & 0.044 & 0.113 & 1.00 & 0.06 & 0.063 & 0.925 & 0.037 & 0.075 \\
fair & -0.232 & -0.095 & 0.252 & 1.00 & 0.327 & 0.319 & 0.857 & 0.382 & 0.143 \\
law & 0.146 & 0.019 & 0.619 & 1.00 & 0.278 & 0.312 & 0.984 & 0.037 & 0.016 \\
image & -0.88 & 0.438 & 0.017 & 1.00 & 0.335 & 0.306 & 0.801 & 0.544 & 0.199 \\
\hline
\end{tabular}

The results presented in the fifth column of both tables indicate the highest mapping level of the individual row and column profiles in the selected space of the second dimension.

In the last part, the analysis of the results for the pair of variables $\left(Y, X_{5}\right)$ will be carried out based on a two-dimensional graph showing the coordinates of individual row and column profiles (Figure 5).

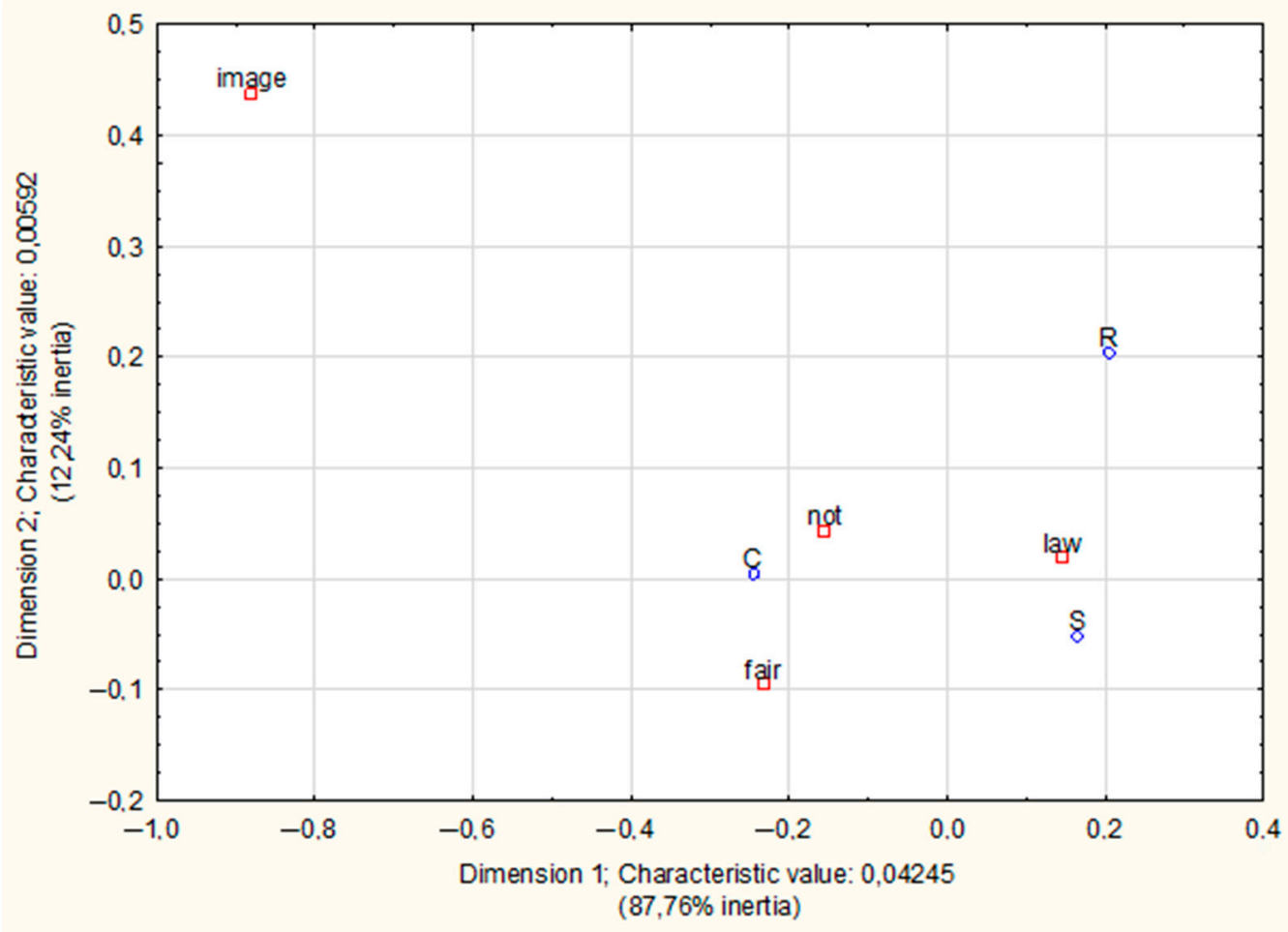

Figure 5. Two-dimensional chart of row and column coordinates for $Y$ and $X_{5}$.

When analyzing both dimensions of space, the first dimension is analyzed at first, which is presented on the chart by the horizontal axis. This dimension has the largest share 
$(87.76 \%)$ in the overall inertia (see Table 7$)$. The chart shows that the horizontal axis, i.e., the first dimension among the group of row profiles, distinguishes between the two groups. On the right side of its center, at a similar distance from it, there are enterprises that reach the $S$ or R level in the continuum model. On the left from the center of the axis, there are companies that achieve the lowest $\mathrm{C}$ level in the CSR model.

Taking into account the column profiles, the horizontal axis also divides the studied enterprises into two groups. On the right, there are companies that meet the obligation to dispose of waste following the applicable law. On the contrary, the left-hand side shows enterprises that conduct waste disposal for the other two reasons, i.e., the company's image and the willingness to remain an honest enterprise, as well as the ones that do not carry out such activities at all.

\section{Discussion}

When discussing the considerations, one should refer to the research problem posed in the initial part, expressed in the form of a question: are the enterprises achieving a higher level of the CSR in the continuum model more responsible towards the environment? In order to address this research problem, questions were asked about the analysis and assessment of the company's impact on the environment in the surveyed company, conscious shaping the rational management of electricity, water, office materials and the motives guiding the company when meeting its waste disposal obligation. The conducted statistical research confirmed the existing relationship only between the two pairs of variables which were further analyzed. In the case of the pair of variables $\left(Y, X_{3}\right)$ it is noticeable that the companies reaching the lowest level of responsibility $(C)$ did not take up conscious actions related to rational water management. The second group of companies, i.e., the ones that achieved the $S$ level (superior), conduct conscious activities related to rational water management, motivating it, on the one hand, with economic issues and, on the other, with the need to care for the environment (a moral obligation). The data presented in Figure 3 also allow noticing the points showing the profile of companies with the R level according to the CSR criterion and also the ones performing activities related to water management only for the image reasons. Both of these profiles have a very low share in the studied sample (about 11\%), thus being distant from other point clusters, which makes their interpretation very difficult, therefore it is omitted to maintain high level of inference.

The data analysis on the CSR level and the motives for implementing the waste disposal obligation (variables $\left(Y\right.$ and $\left.X_{5}\right)$ ) shows that two groups of enterprises are important here (Figure 5). The first group includes enterprises presenting the lowest level (C-common) in the CSR model and, additionally, refraining from the activities related to waste disposal. The second group of enterprises identified in Figure 5 covers the enterprises performing the activities related to waste disposal. These enterprises achieve the $\mathrm{S}$ or $\mathrm{R}$ level in the CSR continuum model. The motives followed by these entities result from the need to meet the obligations imposed by the legal provisions.

The research findings provide the basis for concluding that apart from the area of water management, additionally in the area of waste management, along with the higher-level achievement by enterprises in the CSR continuum model, the examined entities are more responsible for the environment. The obtained results constitute the basis for a positive answer to the question formulated in the research problem only in the two selected areas directly related to environmental protection.

The source literature review addressing employee green behaviour, green attitudes, shows that when examining the factors stimulating employees to pro-ecological involvement, various aspects are taken into account. For example [50] examines the influence of CSR on employee green behaviour through employee well-being and personal environmental norms. Additionally, the research also assumes and examines the environmental strategy role in shaping these relationships. Other authors [51] also researched the factors influencing employees' attitudes and perceptions of corporate social responsibilities. The results of their study show that the largest percentage of employees believe that the CSR 
concept enables generating new values for the sustainability of their business, as well as the sustainable practices in the environment. Another study [52] examined whether people with a higher (or lower) level of positive psychological capital (hopeful thinking, optimism, and resilience) engage more (or less) in the environmentally responsible behaviour in the workplace. It is worth mentioning another paper [53] where the authors explored the influence of corporate social responsibility and three green triggers of environment ( awareness, concern, and knowledge) on employee well-being and green behavior. The aforementioned literature items may become an additional inspiration when creating new concepts for researching factors influencing employee green behavior.

The presented findings of the authors' own research may contribute not only to the understanding of enterprises' commitment to environmental issues, but also may show the motives of entrepreneurs in pursuing the set environmental goals. However, a certain limitation may appear in the form of subjective responses provided by the respondents. One can strive to minimize it by reaching the people competent in answering the questions posed in the study, additionally, quantitative research can be supplemented with qualitative research in the selected cases. Secondly, the obtained research sample could cover a larger group of entities, and thirdly-it is worth not limiting the research to Poland, but also include other countries. As a result, it will be possible to compare the achieved levels of CSR development between the individual countries. If the survey was to be repeated in Poland (on the same research sample) — it would be possible to determine the trends of changes in the achieved CSR levels by economic entities in Poland. It would be interesting research material for further scientific analysis.

Author Contributions: Conceptualization, M.R.-N.; Methodology, M.R.-N. and Ł.K.; Software, Ł.K.; Validation, M.R.-N. and Ł.K.; Data Curation, M.R.-N.; Writing-Original Draft Preparation, M.R.-N.; Writing-Review and Editing, M.R.-N. and Ł.K.; Visualization, M.R.-N. and Ł.K.; Supervision, M.R.N.; Project Administration, M.R.-N.; Funding Acquisition, M.R.-N. All authors have read and agreed to the published version of the manuscript.

Funding: The project is financed by the Ministry of Science and Higher Education in Poland under the programme "Regional Initiative of Excellence" 2019-2022 project number 015/RID/2018/19 total funding amount 10721 040,00 PLN.

Institutional Review Board Statement: The study was conducted according to the guidelines of the Declaration of Helsinki, and approved by the Ethics Committee of the Wroclaw University of Economics and Business, Poland.

Informed Consent Statement: Informed consent was obtained from all subjects involved in the study.

Data Availability Statement: The data presented in this study are available on request from the corresponding author.

Conflicts of Interest: The authors declare no conflict of interest.

\section{References}

1. Low, M.P. Corporate Social Responsibility and the Evolution of Internal Corporate Social Responsibility in 21st Century. Asian J. Soc. Sci. Manag. Stud. 2016, 3, 56-74. [CrossRef]

2. Lockett, A.; Moon, J.; Visser, W. Corporate Social Responsibility in Management Research: Focus, Nature, Salience and Sources of Influence. J. Manag. Stud. 2006, 43, 115-136. [CrossRef]

3. Egri, C.P.; Ralston, D.A. Corporate Responsibility: A Review of International Management Research from 1998 to 2007. J. Int. Manag. 2008, 14, 319-339. [CrossRef]

4. Dahlsrud, A. How Corporate Social Responsibility Is Defined: An Analysis of 37 Definitions. Corp. Soc. Responsib. Environ. Manag. 2008, 15, 1-13. [CrossRef]

5. Taneja, S.S.; Taneja, P.K.; Gupta, R.K. Researches in Corporate Social Responsibility: A Review of Shifting Focus, Paradigms, and Methodologies. J. Bus. Ethics 2011, 101, 343-364. [CrossRef]

6. Withisuphakorn, P.; Jiraporn, P. The Effect of Firm Maturity on Corporate Social Responsibility (CSR): Do Older Firms Invest More in CSR? Appl. Econ. Lett. 2016, 23, 298-301. [CrossRef]

7. Bacinello, E.; Tontini, G.; Alberton, A. Influence of Maturity on Corporate Social Responsibility and Sustainable Innovation in Business Performance. Corp. Soc. Responsib. Environ. Manag. 2019, 27, 749-759. [CrossRef] 
8. Correia, E.; Carvalho, H.; Azevedo, S.G.; Govindan, K. Maturity Models in Supply Chain Sustainability: A Systematic Literature Review. Sustainability 2017, 9, 64. [CrossRef]

9. Stahl, B.C.; Obach, M.; Yaghmaei, E.; Ikonen, V.; Chatfield, K.; Brem, A. The Responsible Research and Innovation (RRI) Maturity Model: Linking Theory and Practice. Sustainability 2017, 9, 1036. [CrossRef]

10. Demir, F. A Strategic Management Maturity Model for Innovation. Technol. Innov. Manag. Rev. 2018, 8, 13-21. [CrossRef]

11. Moutchnik, A. The Maturity Model for Corporate Environmental Management. Umw. Wirtsch. Forum 2015, 23, 161-170. [CrossRef]

12. McAdam, T. How to Put Corporate Responsiblity into Practice. Bus. Soc. Rev. 1973, 6, 8-16.

13. Mirvis, P.; Googins, B.K. Stages of Corporate Citizenship. Calif. Manag. Rev. 2006, 48, 104-126. [CrossRef]

14. Carlisle, Y.M.; Faulkner, D.O. Corporate Social Responsibility: A Stages Framework. Eur. Bus. J. 2004, 16, $143-151$.

15. Visser, W. The Age of Responsibility: CSR 2.0 and the New DNA of Business. J. Bus. Syst. Gov. Ethics 2010, 5, 7-22. [CrossRef]

16. Benn, S.; Edwards, M.; Williams, T. Organizational Change for Corporate Sustainability, 4th ed.; Routledge: London, UK; New York, NY, USA, 2018.

17. Van Marrewijk, M.; Marco, W. Multiple Levels of Corporate Sustainability. J. Bus. Ethics 2003, 44, 107-119. [CrossRef]

18. Aggerholm, H.K.; Trapp, N.L. Three Tiers of CSR: An Instructive Means of Understanding and Guiding Contemporary Company Approaches to CSR? Bus. Ethics 2014, 23, 235-247. [CrossRef]

19. Dyllick, T.; Muff, K. Clarifying the Meaning of Sustainable Business: Introducing a Typology from Business-as-Usual to True Business Sustainability. Organ. Environ. 2016, 29, 156-174. [CrossRef]

20. Gupta, S.; Innes, R. Private Politics and Environmental Management. J. Environ. Econ. Manag. 2014, 68, 319-339. [CrossRef]

21. Amore, M.D.; Bennedsen, M.; Larsen, B.; Rosenbaum, P. CEO Education and Corporate Environmental Footprint. J. Environ. Econ. Manag. 2019, 94, 254-273. [CrossRef]

22. Fisher-Vanden, K.; Thorburn, K.S. Voluntary Corporate Environmental Initiatives and Shareholder Wealth. J. Environ. Econ. Manag. 2011, 62, 430-445. [CrossRef]

23. Amore, M.D.; Bennedsen, M. Corporate Governance and Green Innovation. J. Environ. Econ. Manag. 2016, 75, 54-72. [CrossRef]

24. Sodhi, M.S.; Yatskovskaya, E. Developing a Sustainability Index for Companies' Efforts on Responsible Use of Water. Int. J. Product. Perform. Manag. 2014, 63, 800-821. [CrossRef]

25. Malik, A.; Alam, I.; Faridi, M.R.; Ayub, S. Corporate Social Irresponsibility towards the Planet: A Study of Heavy Metals Contamination in Groundwater Due to Industrial Wastewater. Soc. Responsib. J. 2020, 16, 793-807. [CrossRef]

26. Husser, J.; André, J.M.; Barbat, G.; Lespinet-Najib, V. CSR and Sustainable Development: Are the Concepts Compatible? Manag. Environ. Qual. Int. J. 2012, 23, 658-672. [CrossRef]

27. Kim, E.H.; Lyon, T.P. Strategic Environmental Disclosure: Evidence from the DOEs Voluntary Greenhouse Gas Registry. J. Environ. Econ. Manag. 2011, 61, 311-326. [CrossRef]

28. Heyes, A.; Kapur, S. Community Pressure for Green Behavior. J. Environ. Econ. Manag. 2012, 64, 427-441. [CrossRef]

29. Vitiea, K.; Lim, S. Voluntary Environmental Collaborations and Corporate Social Responsibility in Siem Reap City, Cambodia. Sustain. Account. Manag. Policy J. 2019, 10, 451-475. [CrossRef]

30. Kipper, K. A Neo-Kohlbergian Approach to Moral Character: The Moral Reasoning of Alfred Herrhausen. J. Glob. Responsib. 2017, 8, 196-211. [CrossRef]

31. Belgasem-Hussain, A.A.; Hussaien, Y.I. Earnings Management as an Ethical Issue in View of Kohlberg's Theory of Moral Reasoning. J. Financ. Crime 2020. ahead-of-print. [CrossRef]

32. Gibbs, J.C. Toward an Integration of Kohlberg's and Hoffman's Moral Development Theories. Hum. Dev. 1991, 34, 88-104. [CrossRef]

33. Weber, J. Adapting Kohlberg to Enhance the Assessment of Managers' Moral Reasoning. Bus. Ethics Q. 1991, 1, 293-318. [CrossRef]

34. Arnold, M.L. Stage, Sequence, and Sequels: Changing Conceptions of Morality, Post-Kohlberg. Educ. Psychol. Rev. 2020, 12, 365-383. [CrossRef]

35. Donleavy, G.D. No Man's Land: Exploring the Space between Gilligan and Kohlberg. J. Bus. Ethics 2008, 80, 807-822. [CrossRef]

36. Blum, L.A. Gilligan and Kohlberg: Implications for Moral Theory. Ethics 1988, 98, 472-491. [CrossRef]

37. Vasudev, J.; Hummel, R.C. Moral Stage Sequence and Principled Reasoning in an Indian Sample. Hum. Dev. 1987, 30, 105-118. [CrossRef]

38. Brady, N.; Hart, D. An Exploration into the Developmental Psychology of Ethical Theory with Implications for Business Practice and Pedagogy. J. Bus. Ethics 2007, 76, 397-412. [CrossRef]

39. Crain, W.C. Kohlberg'S Stages of Moral Development in: Theories of Development. In Thories of Development; Prentice-Hall: Hoboken, NJ, USA, 1985; pp. 118-136.

40. Kohlberg, L. The Claim to Moral Adequacy of a Highest Stage of Moral Judgment. J. Philos. 1973, 70, 630-646. [CrossRef]

41. Colby, A.; Kohlberg, L.; Gibbs, J.; Lieberman, M.; Fischer, K.; Saltzstein, H.D. A Longitudinal Study of Moral Judgment. Monogr. Soc. Res. Child Dev. 1983, 48, 1-124. [CrossRef]

42. Paulk, M.C.; Curtis, B.; Chrissis, M.B.; Weber, C.V. Capability Maturity Model for Software, Version 1.1; Software Engineering Institute: Pittsburgh, PA, USA, 1993.

43. CMMI. CMMI ${ }^{\circledR}$ for Services, Version 1.3; Software Engineering Institute: Pittsburgh, PA, USA, 2010. 
44. Kumta, G.A.; Shah, M.D. Capability Maturity Model: A Human Perspective. Delhi Bus. Rev. 2002, 3, 1-14.

45. Crawford, J.K. Project Management Maturity Model, 3rd ed.; Taylor and Francis Group: Abingdon, UK, 2015.

46. Rojek-Nowosielska, M. Corporate Social Responsibility Level-Theoretical Approach. Management 2014, 18, 34-42. [CrossRef]

47. Rojek-Nowosielska, M. CSR Level of Enterprises in Poland: Before and After Transition. In Corporate Social Responsibility in Poland; Springer Nature Switzerland AG: Cham, Switzerland, 2019; pp. 123-133.

48. McHugh, M.L. The Chi-Square Test of Independence Lessons in Biostatistics. Biochem. Med. 2013, 23, 143-149. [CrossRef]

49. Greenacre, M. Correspondence Analysis in Practice; Taylor and Francis Group: Boca Raton, FL, USA, 2017; pp. 1-326.

50. AlSuwaidi, M.; Eid, R.; Agag, G. Understanding the Link between CSR and Employee Green Behaviour. J. Hosp. Tour. Manag. 2021, 46, 50-61. [CrossRef]

51. Melovic, B.; Milovic, N.; Backovic-Vulic, T.; Dudic, B.; Bajzik, P. Attitudes and Perceptions of Employees toward Corporate Social Responsibility in Western Balkan Countries: Importance and Relevance for Sustainable Development. Sustainability 2019, 11, 6763. [CrossRef]

52. Jahanshahi, A.A.; Maghsoudi, T.; Shafighi, N. Employees' Environmentally Responsible Behavior: The Critical Role of Environmental Justice Perception. Sustain. Sci. Pract. Policy 2021, 17, 1-14. [CrossRef]

53. Ahmed, M.; Zehou, S.; Raza, S.A.; Qureshi, M.A.; Yousufi, S.Q. Impact of CSR and Environmental Triggers on Employee Green Behavior: The Mediating Effect of Employee Well-Being. Corp. Soc. Responsib. Environ. Manag. 2020, 27, 2225-2239. [CrossRef] 